\title{
Evaluating the ability of students to learn and utilize a novel telepresence platform, Proximie
}

\author{
Ela Patel ${ }^{1} \cdot$ Anya Mascarenhas $^{2} \cdot$ Subuhee Ahmed $^{3} \cdot$ Daniel Stirt $^{4} \cdot$ Isabella Brady $^{5} \cdot$ Roshane Perera $^{6}$. \\ Jonathan Noël ${ }^{7}$ (1)
}

Received: 11 August 2021 / Accepted: 25 October 2021 / Published online: 6 November 2021

(c) The Author(s), under exclusive licence to Springer-Verlag London Ltd., part of Springer Nature 2021

\begin{abstract}
Novice users of telesurgery could be limited by their experience and technical ability. The impact of the COVID-19 pandemic on health care systems is unprecedented, and telehealth allowed care providers and patients a safety margin. An indirect impact of redeployment of hospital staff during COVID-19 management has been on the reduced educational opportunities for residents. Proximie can be considered as a virtual teaching platform or classroom for any user. Twenty-one students voluntarily participated in utilizing a da Vinci ${ }^{\circledR}$ skills simulator (dVSS) to carry out surgical training simulation tasks. Our study focuses on digital native's adaptation to utilizing Proximie's augmented reality platform to direct task performance, to gauge its feasibility by this unique cohort.
\end{abstract}

Keywords Simulation $\cdot$ Virtual reality $\cdot$ Robotic surgery $\cdot$ Telepresence $\cdot$ Telementoring

\section{Introduction}

Telepresence is the projection of oneself, from a remote location, to create a human-machine-human interface. A machine can be manipulated to allow sensory input in the form of 3-dimensional vision, sound and an instrument's response to the human hand and wrist. This was the start of telerobotics and continues to be the paradigm shift in this surgical practice [1]. Novice users of telesurgery could be limited by their experience and technical ability; and will benefit from developments in telementoring by expert surgeons through virtual reality.

Jonathan Noël

Jonathan.Noel.MD@AdventHealth.com

Trinity Preparatory School, Winter Park, FL 32792, USA

Harvard University, Cambridge, MA 02138, USA

KCU College of Medicine, Kansas City, MO 6410, USA

4 UCF College of Medicine, Orlando, FL 32827, USA

5 Davidson College, Davidson, NC 28035, USA

6 University of Florida, Gainesville, FL 32611, USA

7 AdventHealth Global Robotics Institute, 380 Celebration Place, Celebration, FL 34747, USA
The impact of the COVID-19 pandemic on health care systems is unprecedented, and telehealth allowed care providers and patients the safety margin of distance during a country's lockdown phase [2]. This dramatically increased virtual access to specialist care and consultation, to protect vulnerable communities. The transition to new communication systems is also a humanitarian opportunity for remote and underserved countries to receive democratized specialist health care.

An indirect impact of redeployment of hospital staff during COVID-19 management has been on reduced education for residents. Surgical training in particular, was historically the development of the junior surgeon through the transmission of clinical, technical and behavioral knowledge from the senior surgeon: the apprenticeship model [3]. However, the pandemic diluted the learning experience, as elective operations were deferred, and surgical hospital beds utilized for managing COVID-19 patients [4]. Therefore, virtual patient scenarios and simulated tasks have become the new surgical apprenticeship [5]. Furthermore, an entire generation of students now engage with virtual platforms in their respective high school and college, where technology and the 'online movement' have allowed classes to continue. Students were obligated to pivot their learning style to attend class from home, and challenges were present in socio-economic spheres [6]. However, this new dependence facilitated 
a wider utilization and appreciation of technologies, with varied applications by students.

Proximie is an augmented reality platform that has clinical utility in surgical education from a remote location. It allows mentors to communicate visual and verbally during surgery from virtually anywhere in the globe, so a patient can receive collaborative care instantaneously. Covid19 pandemic augmented the possibility of utilizing such technology to guide and proctor [7]; for instance, during a groundbreaking transatlantic teleproctoring for a complex robotic surgery, whereby an expert surgeon mentored another experienced but procedure naive surgeon through a complex surgery [8]. Proximie can be considered as a virtual teaching podium or classroom for any user, and with the alignment of robotic surgery with telepresence, the feasibility of its use by digital natives was explored. Non-surgical and adolescent personnel have not been formally studied in regard to robotic and Proximie interfaces. Our aim was to investigate perceptions of Proximie from the novice user, to share their insight with the surgical community as a proof of concept.

\section{Methodology}

In June 2021, twenty-one students voluntarily participated in utilizing an Intuitive da Vinci ${ }^{\circledR}$ skills simulator (dVSS) to carry out surgical training simulation tasks. This was used with Proximie platform computers and webcams (video cameras) mounted to side carts. The webcams faced the console, to allow ergonomic guidance and proctoring through live video transmission for participants to virtually annotate and discuss points of proctoring. Proximie is a secure, trustworthy platform with compliance to General Data Protection Regulation (GDPR) and Health Insurance Portability and Accountability Act (HIPAA) regulations. A non-validated questionnaire was used, and each participant completed it after their simulation exercise. This included 12 statements (five-point Likert scale) as well as five short answer questions to capture data on the user's experience. A sample of the questionnaire is shown in Appendix 1.

A protocol was agreed among the junior authors (E.P. and A.M.) and senior author (J.N.) on how the study would be conducted. The brief face-to-face demonstration on console controls and dVSS was delivered around three exercises: 'sea spikes', 'energy pedal control' and 'camera control' shown in Fig. 1.

After initial dVSS training, Proximie was utilized with students carrying out simulation exercises, with guidance at the laptops stationed by the robotic console and remotely. Proximie laptops were in a separate room in and external to the building. Students were primarily supervised by J.N. and were unsupervised to mentor each other, using the program on two separate days (Fig. 2).

\section{Results}

The median age of the users was 16 years old (15-36). The education level of users were high school students $(n=11)$, college students $(n=4)$, medical students $(n=2)$ and Urological surgery fellows $(n=4)$. The laboratory exercise ran over three days, with $3 \mathrm{dVSS}$ consoles and 2 Proximie workstations available. The median scores of answers to questionnaire statements are presented below in Table 1 .

In Fig. 3, Proximie's screen layout is displayed with three out of four available windows utilized, to follow progress in the exercise screen along with the user's physical positioning relative to robotic controls. Any individual who is invited to the Proximie session can view the necessary components of the simulation to teach or learn, respectively, as shown in Figs. 4 and 5.

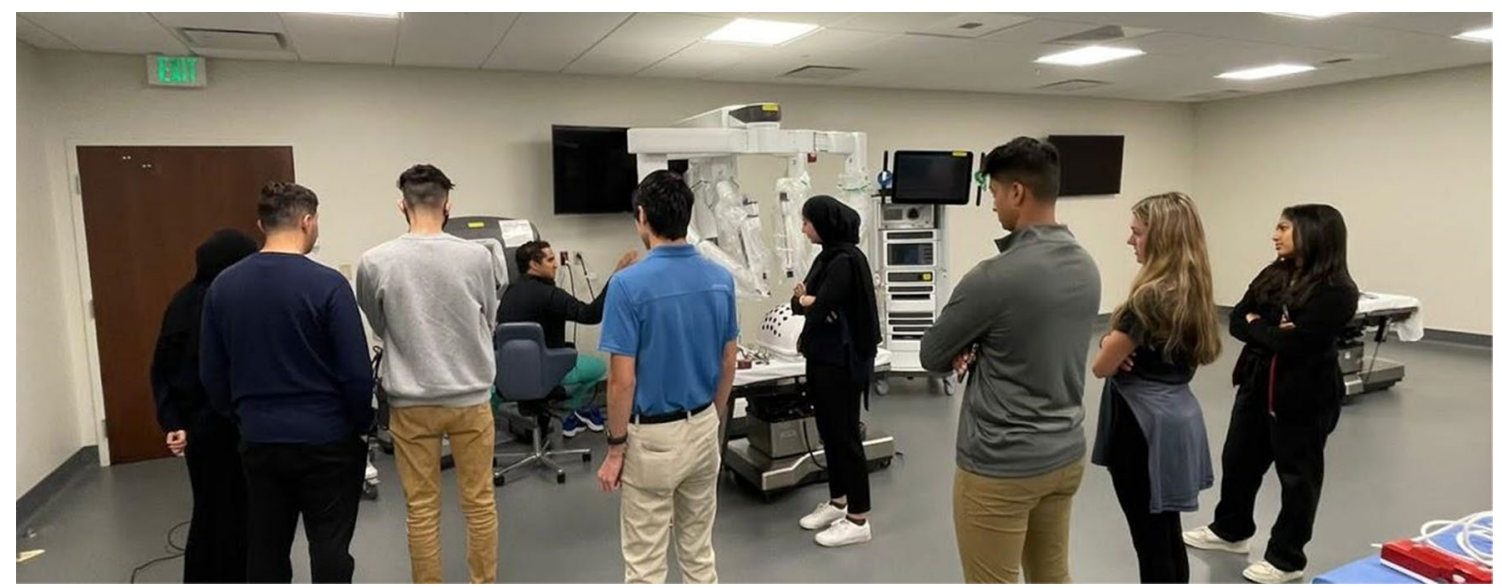

Fig. 1 Mentor (J.N.) explaining the use of dVSS on site 
NICHOLSON CENTER $1^{\text {st }}$ Floor

Advent Health
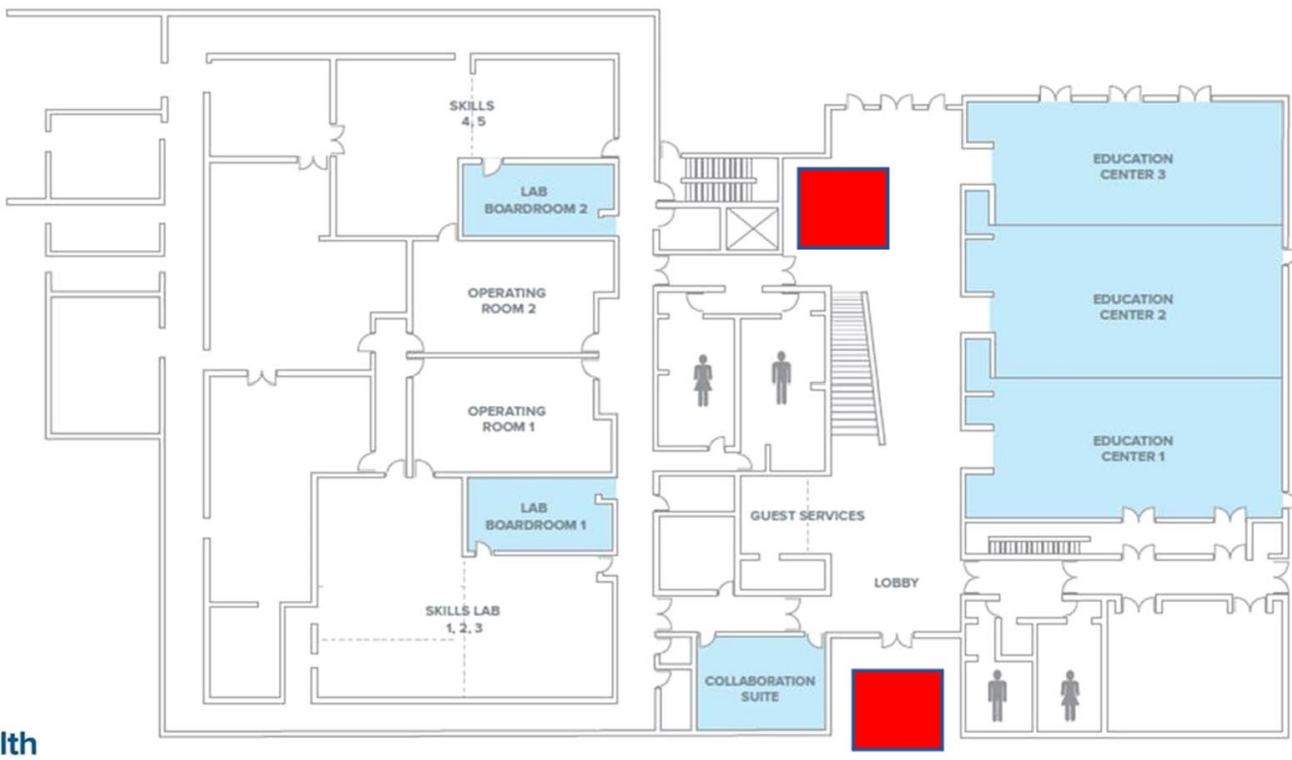

NICHOLSON CENTER $2^{\text {nd }}$ Floor
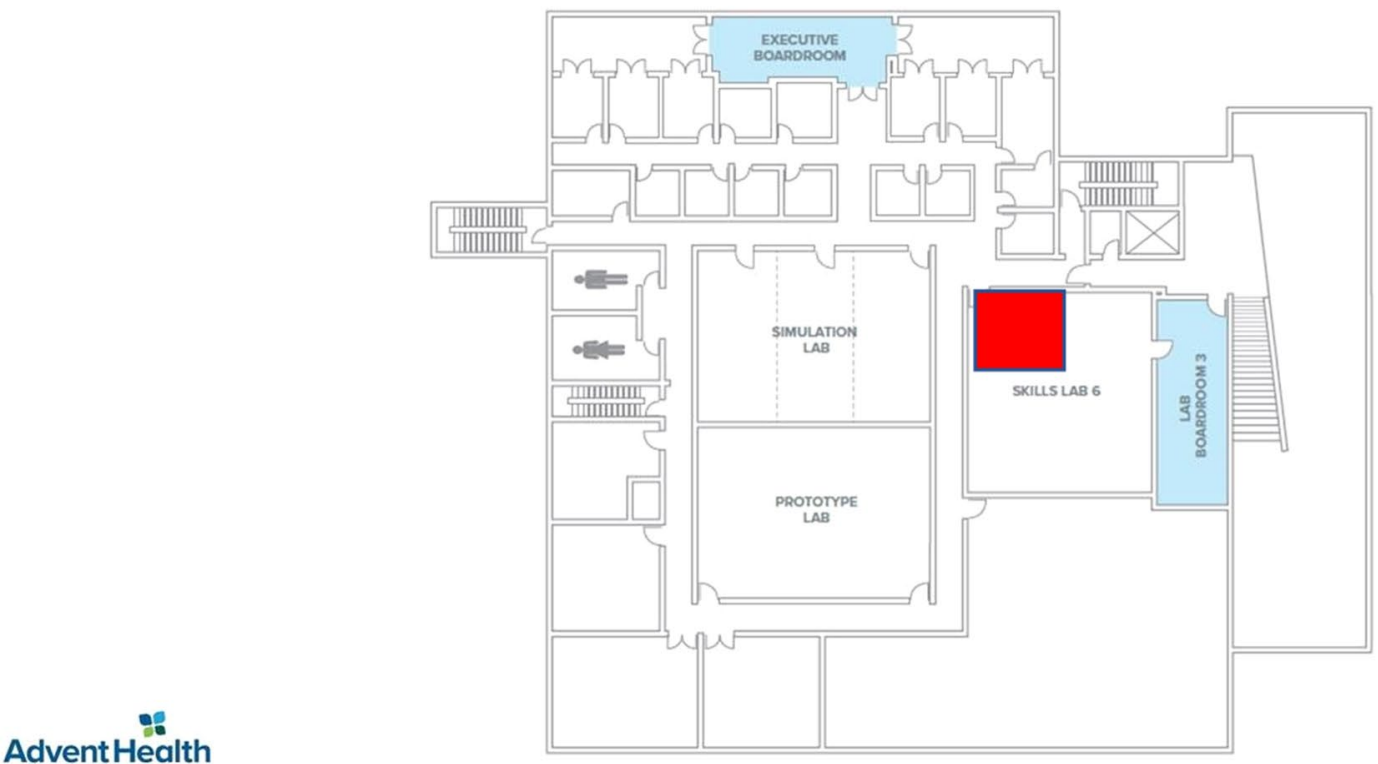

Fig. 2 Floor Plans of Nicholson Center (AdventHealth website). Red squares indicate Mentors and Mentees locations

\section{Discussion}

Telepresence and telementoring has been a transformation in collaborative surgery, supported by virtual reality programs. Telesurgery began at the Defense Advanced Research Projects Agency (DARPA), with the deployment of an armored robotic surgical unit to treat soldiers [9]. NASA supported this technology with the aim to remotely assist astronauts during space expeditions. Telesurgery occurred in September 2001, the surgeon Professor Jacques Marescaux, a
French surgeon, was in New York, and operated transatlantically on a patient in Strasbourg, France to perform a cholecystectomy successfully.

The Covid-19 pandemic has propelled the reliance on real-time communication to perform surgery with expert guidance, to train junior surgeons in unique circumstances [10]. As technology expands to accommodate virtual training, we examined Proximie through a cohort of students from varied education levels that were naïve to the system. All participants joined voluntarily, and this study adhered to 
Table 1 Robotic telementorship questionnaire

\begin{tabular}{|c|c|c|c|}
\hline Response rate (100\%) & Median & Range & Standard deviation \\
\hline Hardware setup was easily understood & 4 & $3-5$ & 0.9979 \\
\hline Proximie technology took up little space & 4 & $1-5$ & 1.1161 \\
\hline Storing was manageable & 5 & $3-5$ & 0.7123 \\
\hline Video feed (augmented reality) was crisp. & 4 & $3-5$ & 0.8536 \\
\hline Audio and visual matched well & 5 & $4-5$ & 0.6016 \\
\hline Audio feedback was minimal or minimized efficiently & 4 & $3-5$ & 0.6882 \\
\hline I would use Proximie again if the opportunity arose & 5 & $2-5$ & 0.7464 \\
\hline I felt able to ask/answer questions during the case & 5 & $3-5$ & 0.5390 \\
\hline Proximie could be useful for me to build or foster independence safely & 4.5 & $3-5$ & 0.8013 \\
\hline The annotations available on Proximie were useful & 5 & $3-5$ & 0.6806 \\
\hline Teaching/Learning with Proximie was a beneficial alternative & 5 & $2-5$ & 0.8106 \\
\hline The experience using Proximie was easier the second time compared to the first & 5 & $5^{\mathrm{a}}$ & 0.2425 \\
\hline
\end{tabular}

KEY: $1=$ strongly disagree, $2=$ disagree, $3=$ neutral, $4=$ agree and $5=$ strongly agree

${ }^{\text {a}}$ No range

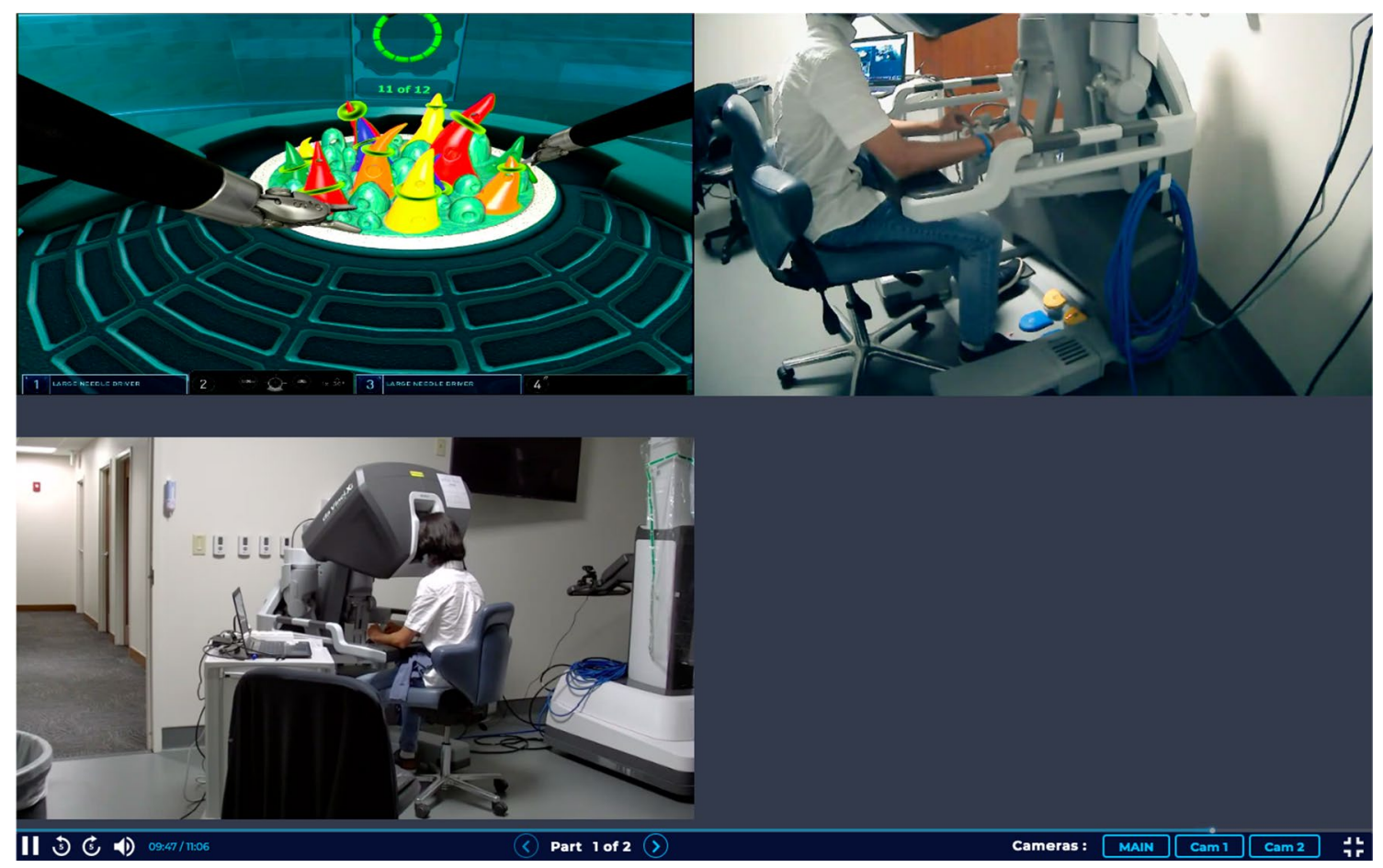

Fig. 3 Participant at dVSS. Proximie captures a simulator view (top left) and an external view of the user at console (top right and bottom left)

all research standards and ethics. The student's adaptation to the simulation exercises was seamless and was further hastened when teleproctored through the platform. This usability of the Proximie platform determines its potential applicability in sectors complimented by healthcare, such as defense [11]. The ease of a robotic surgical nurse or soldier setting up such a system will benefit the mentor and mentee.

dVSS complimented the study's objective as the image projection with stereoscopic vision, endowrist manipulation, camera/clutch control and pedal inputs required complex guidance. It is proposed that digitized medical education in general and simulation-based training in particular, should become the contemporary 'see one, do one, teach one' model [5]. Proximie's multifaceted platform allowed students to access teleproctoring from a laptop, tablet or smartphone. This feature benefits situations of colleagues in isolated or underserved areas, to amplify their access to expertise [12]. Other platforms with similar objectives include companies 

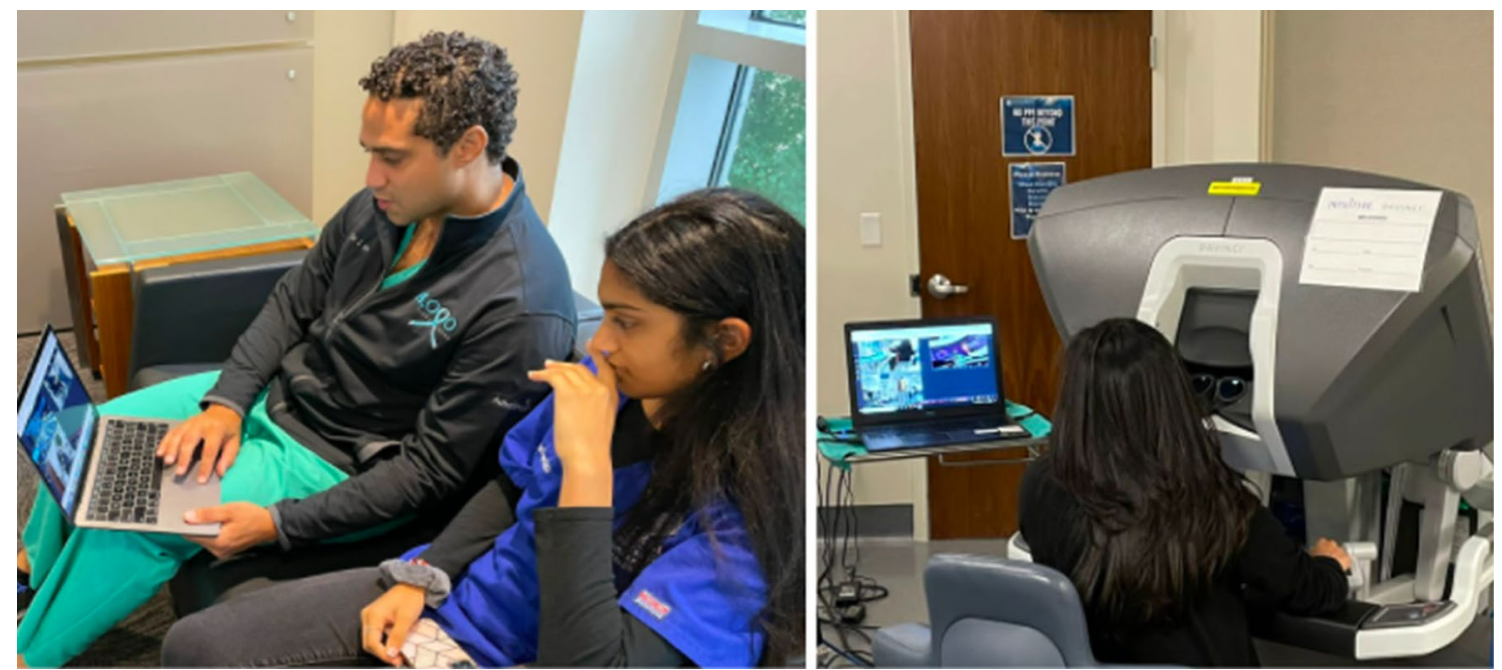

Fig. 4 Two mentors (left) telementoring a participant (right) on the dVSS in a separate floor of the building, by verbal instruction and telestration

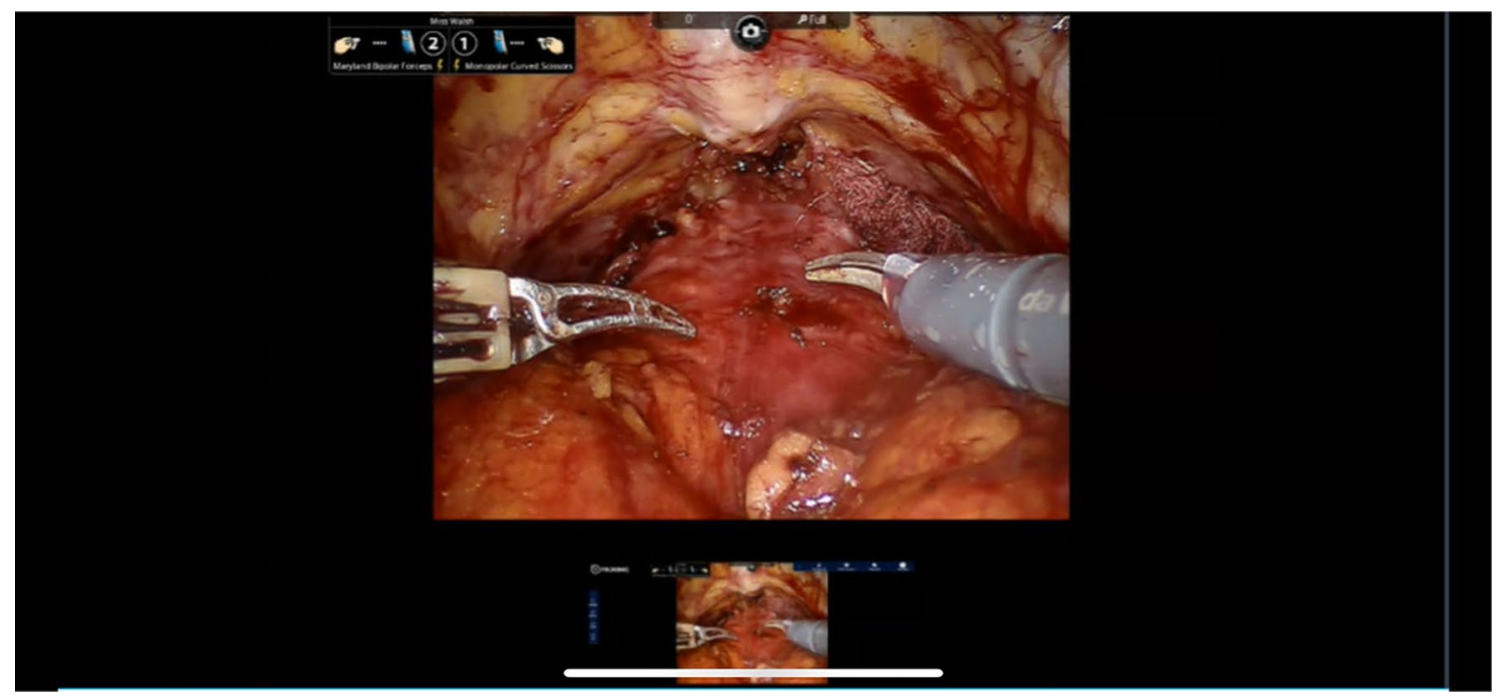

Fig. 5 Endoscopic camera view of live surgery (above) and single screen of Proximie for telementoring (below)

such as Avail telepresence platform, Immertec, utilizing Oculus Quest virtual reality goggles and InTouch Health that offers virtual care for clinic consultations, bedside assessments and intra-operative support.

The questionnaire is non-validated which is a limitation and was answered by students after Proximie to gauge their level of satisfaction. The statements on audio-visual matching, annotations, Proximie as a teaching tool, and benefit aggregation on second use received the highest agreeability. The participants' short answers to the questionnaire revealed the optimal feature was the ability to telestrate during tasks. Any resident seeing a surgeon's precise point of view in real time will bolster future training. There were opinions that the system could be incorporated in high school/college sectors such as mathematics or science. This explains why many students believed that Proximie would be a successful learning tool beyond the surgical realm. The multiple screens were a feature that was favored for readjusting optimal body posture, forearm wrist and hand position. It allowed users to see their own body positioning, overlaid with mentor's drawing instructions.

An area for development was the process of setting up the interface since an on-site technician ensured the system's workflow, the hardware set up and storage was superficially assessed. If the system is to be used globally then it must avoid user intervention to resolve resource conflicts and complicated device configuration. Our exercise recorded only three incidents of momentary freezing, which 
self-resolved, but impacted teleproctoring. An unprotected, non-firewall, open-source network was used for the duration of our Proximie guided simulation which may have impacted image quality. The audio guidance was highly rated, without delays or distortion of voices from mentor or mentee.

A limitation was the sense of disengaging from the dVSS's vision cart to view the Proximie's laptop. Surgical fellows shared concerns of the potential disruption to the learning experience with the same potential during live surgery. Fellows suggested that annotations integrated discretionarily on the console view, will mitigate any distraction in live surgery. The resolution of the Proximie laptop, in comparison to the image of the robotic console, was highlighted to be unmatched. The comparison is unbalanced as the 3D images presented at the dVSS are the result of two continuous-tone monitors for the right and left eye, set to a focus. The differences in 3D compared to $2 \mathrm{D}$ vision is superior when compared to surgical task execution [13]. A simple solution was to link Proximie to the TilePro function to utilize single or multi screens below the operative view, simultaneously (Fig. 5).

\section{Conclusion}

Our study focuses on digital native's utilization of Proximie's augmented reality platform. The Proximie platform successfully allowed teleproctored simulation exercises on the da Vinci ${ }^{\circledR}$ robotic surgical system. The platform allowed students to perform successful telementorship, demonstrating proof of concept in the test of its utility. The areas cited for further success in utilizing this platform are transferable $3 \mathrm{D}$ vision, audio-visual feedback and secure internet connection. The next generation of surgeons will have new tools in information networks and simulations that allow remote transference of skills. An ability to think through and work with these technologies at all education levels, will tailor the continued growth and direction in digital healthcare.

\section{Appendix 1}

Robotic telementorship with:

\section{P) PROXIMIE}

CIRCLE ONE:

HIGH SCHOOL STUDENT

COLLEGE STUDENT

MEDICAL STUDENT

FELLOW

Key: $1=$ strongly disagree, $2=$ disagree, $3=$ neutral, $4=$ agree and $5=$ strongly agree.

\begin{tabular}{|c|c|c|c|c|c|c|c|}
\hline Statements & 1 & 2 & 3 & 4 & 5 & N/A & $\overline{\text { Mean (range) }}$ \\
\hline \multicolumn{8}{|l|}{$\begin{array}{l}\text { 1. Hardware setup } \\
\text { was easily under- } \\
\text { stood }\end{array}$} \\
\hline \multicolumn{8}{|l|}{$\begin{array}{l}\text { 2. Proximie technol- } \\
\text { ogy took up little } \\
\text { space }\end{array}$} \\
\hline \multicolumn{8}{|l|}{$\begin{array}{l}\text { 3. Storing was man- } \\
\text { ageable }\end{array}$} \\
\hline \multicolumn{8}{|l|}{$\begin{array}{l}\text { 4. Video feed (aug- } \\
\text { mented reality) was } \\
\text { crisp. }\end{array}$} \\
\hline \multicolumn{8}{|l|}{$\begin{array}{l}\text { 5. Audio and visual } \\
\text { matched well }\end{array}$} \\
\hline \multicolumn{8}{|l|}{$\begin{array}{l}\text { 6. Audio feedback } \\
\text { was minimal or } \\
\text { minimized effi- } \\
\text { ciently }\end{array}$} \\
\hline \multicolumn{8}{|l|}{$\begin{array}{l}\text { 7. I would use Prox- } \\
\text { imie again if the } \\
\text { opportunity arose }\end{array}$} \\
\hline \multicolumn{8}{|l|}{$\begin{array}{l}\text { 8. I felt able to ask/ } \\
\text { answer questions } \\
\text { during the case }\end{array}$} \\
\hline \multicolumn{8}{|l|}{$\begin{array}{l}\text { 9. Proximie could } \\
\text { be useful for me to } \\
\text { build or foster inde- } \\
\text { pendence safely }\end{array}$} \\
\hline $\begin{array}{l}\text { 10. The annotations } \\
\text { available on Prox- } \\
\text { imie were useful }\end{array}$ & & & & & & & \\
\hline
\end{tabular}




\begin{tabular}{|c|c|c|c|c|c|c|c|}
\hline Statements & 1 & 2 & 3 & 4 & 5 & N/A & Mean (range) \\
\hline $\begin{array}{l}\text { 11. Teaching/Learn- } \\
\text { ing with Proximie } \\
\text { was a beneficial } \\
\text { alternative }\end{array}$ & & & & & & & \\
\hline $\begin{array}{l}\text { 12. The experience } \\
\text { using Proximie was } \\
\text { easier the second } \\
\text { time I used it com- } \\
\text { pared to the first }\end{array}$ & & & & & & & \\
\hline
\end{tabular}

Short answer:

1. What were some specific challenges that you experienced while using Proximie?

2. What are other uses that you believe Proximie could be utilized for?

3. What was the most useful part about using Proximie?

4. How long did it take for you to understand the way Proximie works? Would you say it was fairly time efficient?

5. What do you think could be improved about this technology? Were there any troubles you faced?

Acknowledgements Dr. Nadine Hachach-Haram, Professor Prokar Dasgupta \& Professor Vipul Patel for allowing students to use Proximie and robotic simulation.

\section{Declarations}

Conflict of interest All authors have no disclosures and no conflicts of interest.

Human and animal rights statement This article does not contain any studies with human or animal subjects performed by any of the authors.
2. Dekker PK, Bhardwaj P, Singh T et al (2020) Telemedicine in the wake of the COVID-19 pandemic: increasing access to surgical care. Plast Reconstr Surg Glob Open 9(1):e3228. https://doi.org/ 10.1097/GOX.0000000000003228

3. Carter BN (1952) The fruition of Halsted's concept of surgical training. Surgery 32(3):518-527

4. Karim JS, Hachach-Haram N, Dasgupta P (2020) Bolstering the surgical response to COVID-19: how virtual technology will save lives and safeguard surgical practice. BJU Int 125(6):E18-E19. https://doi.org/10.1111/bju.15080

5. Berte N, Perrenot C (2020) Surgical apprenticeship in the era of simulation. J Visc Surg 157(3 Suppl 2):S93-S99. https://doi.org/ 10.1016/j.jviscsurg.2020.04.003

6. https://www2.ed.gov/documents/coronavirus/reopening-2.pdf. Accessed 31 July 2021

7. Sánchez AS, Vico TD, Hevia MF et al (2021) Telementoring in times of Covid-19 for training in general surgery. Br J Surg. https://doi.org/10.1093/bjs/znab160.052

8. https://www.thetimes.co.uk/article/surgeon-saves-life-with-helpof-virtual-hand-half-a-world-away-265w0bwq7. Accessed 31 July 2021

9. George EI, Brand TC, LaPorta A, Marescaux J, Satava RM (2018) Origins of robotic surgery: from skepticism to standard of care. JSLS. 22(4):e2018.00039. https://doi.org/10.4293/JSLS.2018. 00039

10. Smigelski M, Movassaghi M, Small A (2020) Urology Virtual education programs during the COVID-19 pandemic. Curr Urol Rep 21:50. https://doi.org/10.1007/s11934-020-01004-y

11. https://www.gov.uk/government/news/artemis-jhubmed-deliv ering-innovation-right-where-it-is-needed. Accessed 31 July 2021

12. Greenfield MJ, Luck J, Billingsley ML et al (2018) Demonstration of the effectiveness of augmented reality telesurgery in complex hand reconstruction in Gaza. Plast Reconstr Surg Glob Open 6(3):e1708. https://doi.org/10.1097/GOX.0000000000001708

13. Wagner OJ, Hagen M, Kurmann A, Horgan S, Candinas D, Vorburger SA (2012) Three-dimensional vision enhances task performance independently of the surgical method. Surg Endosc 26(10):2961-2968. https://doi.org/10.1007/s00464-012-2295-3

Publisher's Note Springer Nature remains neutral with regard to jurisdictional claims in published maps and institutional affiliations.

\section{References}

1. Satava RM, Simon IB (1993) Teleoperation, telerobotics, and telepresence in surgery. Endosc Surg Allied Technol 1(3):151-153 